REVISTA DE DERECHO UNED, NÚM. 28, 2021

\title{
ADQUISICIÓN DE UN INMUEBLE POR UNO O AMBOS CÓNYUGES TERMINANDO DE ABONAR SU PRECIO CONSTANTE LA SOCIEDAD DE GANANCIALES
}

\section{ACQUISITION OF A PROPERTY BY ONE OR BOTH SPOUSES, FINISHING THE PAYMEN OF ITS CONSTANT PRICE TO THE SOCIETY OF PROFITS}

\author{
Alejandro F. Gómez-Bello Pagliaro \\ Abogado. Profesor Tutor. Investigador en Formación en la \\ Escuela Internacional de Doctorado de la UNED. \\ Programa de Doctorado en Derecho y Ciencias Sociales \\ agomezbel2@alumno.uned.es
}

Sumario: I. Introducción. II. Que se debe entender por el concepto de "compra a plazos". III. Carácter del inmueble según la fecha de compra. IV. Determinación de los porcentajes del pro indiviso privativo y ganancial. V. Conclusiones. VI. Bibliografía. VII. Índice de resoluciones judiciales. VII.2. Tribunal Superior de Justicia. VII.3. Audiencias Provinciales.

Resumen: Este trabajo busca abordar desde una óptica teórica y práctica, algunos de los problemas que pueden surgir al liquidar la sociedad de gananciales en el supuesto de que uno de los futuros contrayentes adquiere un bien inmueble que se termina de pagar vigente la misma y que se destina a vivienda familiar. Desde el punto de vista teórico lo analizamos a través de estudios doctrinales, de sentencias y resoluciones administrativas. Desde el punto de vista práctico lo hacemos por medio de un ejemplo sobre cómo determinar el porcentaje de pro indiviso privativo y ganancial. Todo ello 
conduce a analizar especialmente el art. 1.357del Código Civil (en adelante CC) que establece la regla general de que los bienes comprados a plazos por uno de los cónyuges y que se termina de pagar ya casado bajo el régimen de gananciales será privativo de éste, y la excepción a esa regla, el art. 1.354 CC, que sería el caso de que el inmueble sea la vivienda familiar.

Palabras clave: Liquidación del régimen de gananciales. Bienes privativos. Bienes gananciales. Proindiviso entre cónyuges y la sociedad de gananciales.

Abstract: This work seeks to address, from a theoretical and practical point of view, some of the problems that may arise when liquidating the community property in the assumption that one of the future contracting parties acquires a real estate that has just been paid for in force and that it is intended for family housing, From the theoretical point of view through doctrinal studies, administrative decisions and resolutions. From a practical point of view, by means of an example on how to determine the percentage of private and joint property undivided. This leads us to analyze especially art. $1.357 \mathrm{CC}$ that establishes the general rule that goods purchased in installments by one of the spouses and that are paid for when married under the community property regime will be exclusive of the latter, and the exception to the rule, art. $1.354 \mathrm{CC}$, which would be the case that the property is the family home.

Keywords: Liquidation of the property regime. Private property. Community property. Undivided between spouses and the community of property.

Recepción original:14-07-2021

Aceptación original:24-07-2021

\section{INTRODUCCIÓN}

Diariamente los distintos operadores jurídicos abordamos las distintas cuestiones que se nos someten en relación a la liquidación de gananciales, y concretamente a los problemas que pueden surgir cuando se ha adquirido un inmueble antes de contraer matrimonio, cuyo pago se aplaza y se abona constante matrimonio. Para resolver dichas cuestiones, es importante conocer primeramente si los pagos a plazos a los que se refiere el art. $1.357 \mathrm{CC}$ se equiparan a los pagos de las cuotas de un préstamo hipotecario y, en su caso, a los pagos de un préstamo personal, otorgado por una 
entidad bancaria o un particular. Es necesario recordar también que ha habido en el Código Civil un cambio de regulación de la sociedad de gananciales en el año 1.981, que tiene gran importancia para determinar el carácter privativo o ganancial del inmueble. En este trabajo veremos igualmente que efectos tiene al liquidar los bienes gananciales si el inmueble se destina simplemente a recreo o en su caso, si se destina como segunda vivienda familiar. Dentro de los múltiples conflictos que se presentan en la liquidación de la sociedad de gananciales, nos encontramos que uno de cónyuges alega que ha pagado íntegramente con dinero privativo las cuotas del préstamo constante el matrimonio, por lo que abordamos este asunto citando jurisprudencia.

Determinado que existe un proindiviso privativo y ganancial sobre el inmueble, procede fijar los porcentajes de cada uno, por lo que es preciso saber claramente el precio de adquisición del bien, estudiando en este punto si ha de computarse solamente el principal del préstamo o también los intereses. Igualmente es preciso conocer que cantidad de dinero se pagó antes del matrimonio, durante el matrimonio y tras la disolución de la sociedad de gananciales, por ello haremos hincapié en estos aspectos estudiando la doctrina científica y diversas sentencias de las Audiencias Provinciales, que no siempre mantienen un criterio uniforme. Para finalizar, y a efectos de ayudar a la comprensión de la materia, transcribiremos unos ejemplos sobre cómo calcular el importe abonado del préstamo hipotecario antes, durante y con posterioridad al matrimonio.

\section{QUE SE DEBE ENTENDER POR EL CONCEPTO DE “COMPRA A PLAZOS"}

Establece el Código Civil en su artículo 1.357: "Los bienes comprados a plazos por uno de los cónyuges antes de comenzar la sociedad tendrán siempre carácter privativo, aun cuando la totalidad o parte del precio aplazado se satisfaga con dinero ganancial.

Se exceptúan la vivienda y ajuar familiares, respecto de los cuales se aplicará el art. 1.354."

Este precepto hace referencia al supuesto en que el comprador entrega una cantidad al adquirirlo y aplaza el resto del pago; la doctrina mayoritaria y la jurisprudencia han interpretado que se equiparan estos pagos aplazados de la compraventa a las amortizaciones 
de la hipoteca. Entre ellos ANTONIO JAVIER PÉREZ MARTÍN ${ }^{1}$, o JUAN MONTERO AROCA ${ }^{2}$, quien además recuerda que hay que tener en cuenta si el inmueble será o no posteriormente vivienda familiar, puesto que si no lo fuera ha de estarse al primer párrafo del art. 1.357 CC y por tanto será privativo de quien lo ha adquirido, independientemente de que se haya pagado con dinero ganancial.

\section{En el mismo sentido, MARTA SOLEDAD SEBASTIÁN CHENA³.}

En cuanto a la jurisprudencia, esta cuestión ha sido analizada por primera vez por la Sentencia del Tribunal Supremo (en adelante STS) de 31 de octubre de $1.989^{4}$ que resuelve la controversia equiparando las amortizaciones de la hipoteca y los pagos de una compraventa a plazos, aplicando por tanto lo dispuesto en el art. 1.357 CC en relación con el art. 1.354 del mismo texto legal que declaró que el inmueble que adquirió un cónyuge antes de contraer matrimonio y que terminó abonando constante matrimonio pertenecía en pro indiviso al cónyuge y a la sociedad de gananciales en proporción a los pagos efectuados.

1 PÉREZ MARTíN, A. J., Tratado de Derecho de Familia, Volumen 1: Regímenes Económicos matrimoniales, Constitución, funcionamiento, disolución y liquidación. Lex Nova, pág. 475 y 476. Valladolid. 2.009, afirma que una compraventa puede tener lugar abonando el comprador al vendedor la totalidad del precio cuando se celebra el contrato (compra al contado) o bien, entregando en ese momento una cantidad y aplazando el resto en un determinado período de tiempo (compra a plazos). Cuando el art. 1.357 del CC hace referencia al pago a plazos se está refiriendo a la segunda modalidad. No obstante, surge la duda de si dentro del pago al contado pueden incluirse aquellos supuestos en los que el comprador tiene necesidad de pedir un préstamo a una entidad bancaria o a un tercero para pagar el precio de la compraventa. En puridad, y desde el punto de vista del vendedor no cabe hablar de compraventa con aplazamiento de pago, ya que él ha cobrado la totalidad del precio, sin embargo, desde el punto de vista que ahora interesa, esto es para determinar el carácter ganancial o privativo de un inmueble, este tipo de compraventa tiene la consideración de pago aplazado.

2 MONTERO AROCA, J., Disolución y liquidación de la sociedad de gananciales. $4^{\circ}$ ed. Tirant lo Blanch, Pág. 376 a 379. Valencia, 2.014. Si se trata de cualquier inmueble, que no sea la que después es la vivienda familiar, debe estarse a los dispuesto al artículo 1357, I, CC, de modo que ese bien será privativo de quien lo adquirió, independientemente de la parte del precio que se pague con ese dinero ganancial. Si se convierte durante el matrimonio en vivienda familiar, habrá de estarse, dada la remisión del artículo 1.357, II, a lo dispuesto en el artículo 1.354, conforme al cual la propiedad se tendrá pro indiviso entre el cónyuge y la sociedad de gananciales. Esta norma especial debe aplicarse sobre todo para el caso habitual del préstamo hipotecario, esto es, el pagar en la escritura de compra aparentemente todo el precio de la vivienda, pero hipotecándola al mismo tiempo, no puede entenderse en el sentido de que no ha habido plazos pagados con dinero ganancial.

3 SEBASTIÁN CHENA, M ${ }^{\mathrm{a}}$. S. La liquidación de la Sociedad de gananciales, enfoque práctico de los aspectos sustantivos, Tirant Lo Blanch, pág. 173. Valencia, 2.016.

4 Roj: STS 9260/1989 - ECLI:ES:TS: 1989:9260 
Razona el Alto Tribunal que resuelve todo ello en base de una justicia material rectamente entendida y superadora de ciertos excesos formalistas, propiciadores incluso del fraude de ley que podría suponer entender como decisivo y determinante el hecho formal de que quien compra una vivienda familiar en estado de soltería y en vísperas de contraer matrimonio, constituyendo al propio tiempo una hipoteca sobre aquél a pagar a lo largo de dicho matrimonio, pueda sostener, burlando el espíritu del párrafo $2{ }^{\circ}$ del art. 1.357 que ese concreto bien (o sea la vivienda y ajuar familiares) es y sigue siendo privativo, pese a que las amortizaciones del crédito hipotecario constituido paralelamente se hagan efectivas en definitiva durante el matrimonio, resultando patentes en todo caso la equiparación a estos efectos entre dichas amortizaciones de la hipoteca y los pagos de una compraventa a plazos. Las Audiencias Provinciales por su parte mantienen un criterio idéntico al del Tribunal Supremo. Así la Sentencia de la Audiencia Provincial (en adelante AP) de Vizcaya, sec. $4^{\mathrm{a}}$, S 20-6-2.011, $\mathrm{n}^{\circ} 448 / 2.011$, rec. 180/2.0115; Sentencia de la AP A Coruña, sec. 5a , S 12-11-2.010, no 400/2.010, rec. 71/2.0106; Sentencia de la AP Madrid, sec. 25 a S 17-1-2.007, no 15/2.007, rec. $302 / 2.006^{7}$, por citar algunas.

Antes hemos transcrito el artículo $1.357 \mathrm{CC}$ y hemos mencionado el artículo $1.354 \mathrm{CC}$ con el que está relacionado. Dice este precepto: "Los bienes adquiridos mediante precio o contraprestación, en parte ganancial y en parte privativo, corresponderán pro indiviso a la sociedad de gananciales y al cónyuge o cónyuges en proporción al valor de las aportaciones respectivas."

Si prestamos atención a su redacción, veremos que utiliza la palabra "adquirir", sin embargo, el artículo 1.357 CC usa la palabra "comprar".

A esta diferencia de conceptos la aborda jurídicamente la Resolución de la DGRN de 29 de marzo de $2.010^{8}$, basándose en el criterio mantenido por el Tribunal Supremo. Esta Resolución establece en su fundamento jurídico tercero que a diferencia de los arts. $1.354 \mathrm{y}$ 1.356 del Código Civil que hacen referencia a "bienes adquiridos", lo que parece presuponer la necesaria consumación del proceso transmisivo para que el bien adquiera naturaleza privativa o ganancial en

\footnotetext{
ROJ: SAP BI 394:2011, ECLI: ES: APBI:2011:394

ROJ: SAP C 3227:2010, ECLI: ES: APC:2010:3227

ROJ: SAP M 1052:2007, ECLI: ES: APM:2007:1052

DGRN. Resolución de 29-3-2010. BOE 132/2010, de 31 mayo 2.010.
} 
los supuestos a que se refieren, el art. 1.357 antes reseñado presenta la particularidad de referirse a "bienes comprados".

Continúa explicando la Resolución que esta expresión revela que para el Código Civil basta que el contrato se haya perfeccionado para considerar el bien como privativo, aunque la adquisición del dominio por efecto de la tradición tenga lugar con posterioridad al momento en que haya comenzado a regir la sociedad de gananciales (cfr. arts. 1.445 y 1.450 del CC), sin perjuicio del correspondiente derecho de reembolso respecto de la parte del precio aplazado que sea satisfecho con cargo a fondos gananciales (cfr. art. 1.358 del Código Civil ).

Concluimos por tanto que la doctrina, la jurisprudencia del Tribunal Supremo así como las resoluciones de las Audiencias Provinciales equiparan estos pagos aplazados de la compraventa a la que se refiere la norma con las amortizaciones de la hipoteca.

Cabe ahora analizar si también se equipara el dinero o préstamos que no provienen de un préstamo hipotecario.

La profesora SEBASTIÁN CHENA ${ }^{9}$, sostiene que es indiferente si al préstamo hipotecario o personal lo ha concedido una entidad bancaria, o ha sido un préstamo de un familiar o un amigo.

Igualmente, PÉREZ MARTÍN ${ }^{10}$, quien afirma que lo determinante es que constante la sociedad de gananciales se abone con dinero común parte del precio de la vivienda. Por tanto, resultará indiferente si se concertó un préstamo hipotecario, uno personal, o si el dinero lo prestó un familiar.

Por su parte así también lo vienen entendiendo el Tribunal Supremo y las Audiencias Provinciales. A modo de ejemplo, la STS 9 de marzo $1.998^{11}$, que dando por acreditado que las hermanas de la esposa le prestaron cierta cantidad de dinero para el abono del inmueble, y que, constante matrimonio, se devolvió el préstamo con dinero ganancial, es de aplicación el art. 1354 del CC., o la SAP de Álava de 21 junio $2007^{12}$ en la que el comprador de la vivienda era un empleado de banca, y no le hizo falta un préstamo hipotecario sino uno personal.

Como dice MONTERO AROCA ${ }^{13}$, un aspecto distinto es el que a veces la poca duración del matrimonio lleva a que la aplicación de

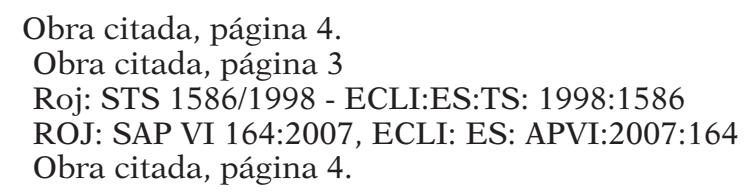


la norma lleve al ridículo. Es el caso que aborda la SAP Madrid de 8 septiembre $2.006^{14}$, en el que un hombre soltero había comprado la vivienda con un préstamo hipotecario y empezó a pagarlo, luego contrajo matrimonio que duró el matrimonio duró desde el 1 de septiembre de 2.001 hasta el 30 de junio de 2.002 .

Finalmente, como dicen PÉREZ MARTÍN ${ }^{15}$ y SEBASTIAN CHENA $^{16}$, no existe compraventa a plazos cuando el cónyuge abona la totalidad del precio antes de casarse y con posterioridad se otorga la escritura pública, abonándose por la sociedad de gananciales los gastos e impuestos que conlleva ella y su correspondiente inscripción en el Registro de la Propiedad.

\section{CARÁCTER DEL INMUEBLE SEGÚN LA FECHA DE COMPRA}

Tal como afirma PÉREZ MARTÍN ${ }^{17}$, hay que tener en cuenta que la Ley 11/1.981 de 13 de mayo de 1.981 modificó la regulación de la sociedad de gananciales que se contenía en el Código Civil, no teniendo carácter retroactivo la reforma, que tiene una importante repercusión en el momento de calificar el carácter ganancial o privativo de los bienes, cuestión ésta muy específica y que se escapa a muchos operadores jurídicos.

Si la vivienda se adquirió a plazos por uno de los cónyuges antes del matrimonio, tendrá carácter privativo, ya que no existía un precepto similar al art. 1.357 del actual CC, estando vigente antes de esa fecha el art. 1.396 CC.

Por tanto, habrá que estar a si la fecha de compraventa de la vivienda ha sido anterior o posterior al 13 de mayo de 1.981. Como bien expone la SAP Valencia, de 8 de junio de $2.006^{18}$, la vivienda había sido adquirida antes del 13 de mayo de 1.981, lo que implica que se aplica para resolver la cuestión el artículo 1.396 del CC y por tanto acuerda que la vivienda es privativa.

Como afirma SEBASTIÁN CHENA ${ }^{19}$ al amparo del (hoy derogado) artículo 1.396 CC, si la vivienda se adquirió antes del 13 de mayo de 1.981 el bien tiene carácter privativo, con independencia

\footnotetext{
14 ROJ: SAP M 11174:2006, ECLI: ES: APM:2006:11174

15 Obra citada, página 3

16 Obra citada, página 4.

17 Obra citada, página 3

18 ROJ: SAP V 1951:2006, ECLI: ES: APV:2006:1951

19 Obra citada, página 4.
} 
de que sea la vivienda familiar, y habrá que incluir como partida del Activo el valor actualizado de los plazos abonados constante la sociedad de gananciales con cargo a fondos comunes, es decir la sociedad será acreedora del cónyuge adquirente. El Tribunal Supremo se ha pronunciado en numerosas sentencias sobre esta cuestión acordando que el inmueble tiene carácter privativo haya sido o no vivienda familiar. Véanse las STS de 04 de octubre de $1.999^{20}$, STS de 4 diciembre de $2.002^{21}$ y la STS de 3 de noviembre de $2.006^{22}$. Por su parte diversas sentencias de las Audiencias Provinciales resuelven en el mismo sentido que el TS. Por todas la SAP Asturias, de 17 de mayo de $2.007^{23}$.

A partir de la Ley 11/1.981 de 13 de mayo, afirma LINACERO DE LA FUENTE ${ }^{24}$, se establece un sistema más justo, y de la regla general del art. 1357.1 CC, se exceptúa el caso de la vivienda y ajuar familiares, a las que se refiere el art. 1.354. En consecuencia, dice, si el precio o contraprestación es en parte privativo y en parte ganancial, la vivienda o ajuar corresponderá proindiviso a la sociedad de gananciales y al cónyuge o cónyuges en proporción a sus respectivas aportaciones. Indica asimismo que lo anterior supone una variación en las cuotas de cada titular mientras se están pagando los plazos, una "copropiedad variable" no prevista en nuestras leyes y de difícil acceso al Registro de la Propiedad. Concretamente sobre el acceso al Registro de la Propiedad, BELDA CASANOVA ${ }^{25}$, pone en relación el art. 91 del Reglamento Hipotecario y el art. 1357.2 CC. Afirma que el documento que accede al Registro de la Propiedad hace constar el carácter privativo, constando igualmente como privativa la deuda garantizada con la hipoteca. El propietario, sencillamente, no tiene que volver a pasar por el Registro de la Propiedad para nada. Se pregunta entonces cuál es el documento que servirá para operar la modificación registral que recoja el carácter privativo o ganancial del precio aplazado. Uno, dice, podría ser la carta de pago del acreedor si no fuera por lo inusual de la intervención de los deudores en su otorgamiento. Otra vía formal para recoger el consentimiento de los cónyuges sería el acta de entrega del capital pendiente. Explica

\footnotetext{
20 Roj: STS 6069/1999 - ECLI:ES:TS: 1999:6069

21 Roj: STS 8139/2002 - ECLI:ES:TS: 2002:8139

22 Roj: STS 6785/2006 - ECLI:ES:TS: 2006:6785

23 ROJ: SAP O 1319:2007, ECLI: ES: APO:2007:1319

24 LINACERO DE LA FUENTE, M. Tratado de derecho de Familia. Aspectos Sustantivos. Tirant Lo Blanch. Pág. 250. Valencia, 2.016.

${ }_{25}$ BELDA CASANOVA, C. "El artículo 1357.2 del código civil o una forma irregular de aportación a la sociedad de gananciales". Diario La Ley, Sección Doctrina, 1998, Ref. D-70, tomo 1, 1.998, Pág. 8 a 12.
} 
que suele ser frecuente en los préstamos concedidos para financiar construcciones que el importe queda aplazado parcialmente, y es entregado a medida que se efectúa la obra. Pues bien, añade, en el momento de formalización del acta notarial de recepción de la cantidad aplazada podría darse la comparecencia de ambos cónyuges y la consignación de las dos manifestaciones que provocarían la rectificación registral: que es vivienda habitual y que se ha satisfecho con dinero ganancial. La tercera vía sería la escritura pública otorgada por ambos cónyuges en la que se solicita la rectificación registral, haciendo constar, por una parte, que la vivienda que pertenece privativamente a uno es vivienda habitual, y por otra que la cantidad "X" que supone el total o una parte del precio aplazado que costa en el Registro de la Propiedad ha sido satisfecha con cargo a la sociedad de gananciales.

Sobre la protección registral, SEBASTIÁN CHENA ${ }^{26}$, expone que es poco habitual que un matrimonio adopte las precauciones a las que se refiere el art. 91 del R.H., siendo frecuente en la práctica que el cónyuge titular, sobre todo cuando ya nadie reside en la vivienda familiar, y una vez disuelta la sociedad de gananciales, haya procedido a vender tal vivienda sin contar con su ex cónyuge, ya que al figurar registralmente a su nombre y no constar que sea vivienda habitual, bastará con que manifieste en la escritura de venta que no posee tal carácter para que la venta se lleve a efecto. En tal caso, continúa diciendo, habrá una enajenación fraudulenta que, conforme a los artículos 1.390, 1.391 y 1397.2 del CC, dará lugar a la inclusión en el activo de la sociedad: "El importe actualizado del valor que tenían los bienes al ser enajenados por negocio ilegal o fraudulento si no hubieran sido recuperados".

La adquisición de la vivienda con posterioridad al 13 de mayo de 1.981 pues nos sitúa ante el régimen jurídico actual o sea que la vivienda o ajuar corresponderá pro indiviso a la sociedad de gananciales y al cónyuge o cónyuges en proporción a sus respectivas aportaciones. Explica el profesor VILLAGRASA ALCAIDE ${ }^{27}$, que los art. $1.354,1.356$ y 1.357 del $\mathrm{CC}$ establecen reglas que conviene analizar conjuntamente. Nos dice el profesor, que el art. 1.354 CC establece que los bienes adquiridos mediante precio o contraprestación en parte ganancial y en parte privativo corresponden pro indiviso a la sociedad de gananciales y al cónyuge o cónyuges en proporción al valor de sus aportaciones. Pero advierte que el art. 1.356 establece

26 Obra citada, página 4.

27 VILlAGRASA ALCAIDE, C., Derecho de Familia. Ed. Bosch. 1ª Edición, Pag.196, Barcelona, 2.011. 
una excepción para el caso de bienes adquiridos a plazos constante la sociedad que tendrán carácter ganancial o privativo en función de la procedencia con que se hubiera satisfecho el primer plazo. Continúa diciendo que es lógico considerar que la misma norma rige para los bienes adquiridos a plazos antes de la sociedad de gananciales, puesto que entonces el primer plazo es necesariamente privativo (art. 1.357- $1^{\circ} \mathrm{CC}$ ). Si lo plazos siguientes se abonan con bienes distintos al primero, surgirán créditos a favor o en contra de la sociedad, en aplicación del art. 1.358 CC. Por último, concluye, se exceptúan de esta regla la vivienda y ajuar familiares, sobre los que rige el art. 1.354 CC. Así por ejemplo si la vivienda familiar se adquirió antes de la vigencia de la sociedad de gananciales, pertenecerá por indiviso a los cónyuges, en proporción al dinero privativo que haya invertido en ella, y a la sociedad de gananciales, también en proporción al dinero ganancial que se haya destinado a la adquisición. En igual sentido SEBASTIÁN CHENA ${ }^{28}$, indica que existirá un proindiviso sobre el bien entre la sociedad de gananciales y el cónyuge o cónyuges en proporción a sus aportaciones respectivas, siendo el efecto en la liquidación de gananciales que sólo se incluirá en el Activo el porcentaje ganancial y respecto a la parte privativa habrá que proceder a extinguir el condominio que pudiera existir entre los cónyuges o ex cónyuges. Recomienda tener muy presente este cambio legislativo, ya que, en caso de liquidación en vía judicial, si no se alega por el letrado esa modificación legislativa, el juez no podrá considerarla de oficio, tal como recoge la SAP Madrid de 19 de noviembre de $2.002^{29}$. Hay sin embargo alguna resolución judicial que opta por considerar ganancial en su totalidad e incluir en el pasivo un crédito frente a cada uno de los cónyuges por el importe que hicieron antes de casarse cuando la compra la hicieron ambos antes de contraer nupcias ${ }^{30}$.

Si leemos con atención el art. 1.357-2 ${ }^{\circ} \mathrm{CC}$, veremos que se refiere a la vivienda familiar, en singular. Esto conlleva a estudiar si ese carácter de familiar se aplica solo al inmueble que sirve de hogar o puede extenderse a otros inmuebles. BERJANO ARENADO ${ }^{31}$, afirma que debe entenderse, como lo hace la doctrina al interpretar los

28 Obra citada, página 4.

29 Id. Cendoj: 4375a103.rtf. SAP Madrid, rec. 469/2.002, 19-11-2.002.

30 ROJ: SAP MA 828:2008, ECLI: ES: APMA:2008:828. SAP Málaga, $n^{\circ}$ 165/2.008, de 26-3-2.008.

31 BERJANO ARENADO, F., "Constitución de hipoteca a cargo del matrimonio sobre vivienda adquirida por precio aplazado en estado de soltería. ¿carácter privativo o ganancial?" Foro Abierto. Boletín de Contratación inmobiliaria. El Derecho Editores. 2.004. Pág. 3. 
arts. 1.320 y $1357-2^{\circ}$ del CC, que podrían existir más de una vivienda "familiar", entendiendo por tal aquella que pueda ser la habitual o la "normal y de presumible continuación" o la que presente "los caracteres de habitabilidad, habitualidad y carácter familiar", quedando fuera de dicha calificación lo que pudieran ser "residencias secundarias, viviendas de temporada o fincas de recreo". MORENO GARCÍA ${ }^{32}$, afirma que perfectamente pueden existir dos viviendas familiares (por las razones que fueren) si se cumple el requisito de la habitualidad predicable de la residencia de las mismas y que obviamente no se cumple en las viviendas de recreo.

En los apartados anteriores hemos visto cómo la vivienda tiene carácter privativo si ha sido adquirida a plazos por un cónyuge en estado de soltero antes del 13/05/1.981 aunque se haya abonado parte del precio con cargo a la sociedad de gananciales y también cuando después de esa fecha se compra la vivienda y ésta no tiene carácter familiar.

También que en aplicación de los artículos 1.357 CC y 1.354 CC, la vivienda pertenecería en proindiviso al cónyuge que compró en estado de soltero y a la sociedad de gananciales en la proporción que corresponda.

Hay sin embargo una Sentencia del Tribunal Supremo ${ }^{33}$, que analiza un supuesto en el que el esposo había comprado la vivienda antes del 13 de mayo de 1.981, pero entiende que no es privativa, sino que tiene carácter ganancial porque los pagos que se hicieron antes del matrimonio fueron "en atención al futuro enlace y con evidente intención por compensación con otros gastos". Dice su Fundamento de Derecho Cuarto que la parte de precio que se pagó antes del matrimonio del primer inmueble citado, conforme a documentos privados, obedeció al futuro enlace matrimonial "con evidente intención por compensación con otros gastos", lo que paladinamente demuestra que no podía atribuirse la exclusividad de la propiedad del dinero al marido y así se deduce de los actos consiguientes, pues al otorgarse la escritura pública de la referida compra, esto es contraído matrimonio, no se hizo constar, según se podía haber realizado, el carácter privativo, al menos parcial, del dinero invertido en

32 MORENO GARCÍA, J.A, "Constitución de hipoteca a cargo del matrimonio sobre vivienda adquirida por precio aplazado en estado de soltería. ¿carácter privativo o ganancial?" Foro Abierto. Boletín de Contratación inmobiliaria. El Derecho Editores. 2.004. Pág. 3.

33 Roj: STS 1962/1993 - ECLI:ES:TS: 1993:1962 
la compraventa, de donde se infiere que en este primer punto no se ha infringido el precepto invocado.

¿Qué sucedería si un cónyuge alegara que los pagos, vigente la sociedad de gananciales, se han efectuado enteramente con dinero privativo y no ganancial? Naturalmente deberá acreditarlo suficientemente. Un supuesto así ha conocido la SAP Barcelona de 20 de septiembre de $2.007^{34}$, en el que se planteaba por una de las partes que las cuotas del préstamo hipotecario estaban domiciliadas en una cuenta de titularidad exclusiva que se nutría únicamente de los ingresos que hacían sus padres. Establece la Sentencia en su Fundamento de Derecho Cuarto que adquirida que fue la vivienda por la esposa actora con anterioridad al matrimonio, aunque parte del precio quedó aplazado mediante la constitución de una hipoteca, lo cierto es que el esposo nunca fue titular de dicho préstamo hipotecario, y además éste fue amortizándose a través de una cuenta bancaria de la que eran titulares indistintos únicamente la demandante y sus dos progenitores, a quienes se les libró precisamente - a nombre del padre y 2 titulares más- el certificado de la liquidación total del préstamo hipotecario, sin que conste acreditado que el demandado hubiere aportado cantidad alguna a la referida cuenta privativa de la esposa y de sus padres, lo que hace decaer, sin más, su petición de que el precio que resultó aplazado para la adquisición de la vivienda familiar deba incluirse en el patrimonio de la sociedad de gananciales, al haber quedado del todo punto acreditado, cual antes se ha expresado, el carácter privativo del dinero con el que se fue satisfaciendo todas y cada una de las cuotas del préstamo hipotecario de constante referencia. En otro supuesto, la AP de Madrid de 19 de noviembre de $2.002{ }^{35}$, llegó a la conclusión de que la vivienda era ganancial, a pesar de que existía un contrato privado de compraventa con fecha anterior al matrimonio, porque no se había acreditado que se hiciesen pagos antes de contraer las nupcias. Establece la Sentencia en su Fundamento de Derecho Tercero que en ningún caso, y por ningún medio probatorio, y de conformidad con lo establecido en el artículo 217 de la Ley de Enjuiciamiento Civil , el esposo acredita la realidad de tales desembolsos económicos, dada la inexistencia de documento alguno al respecto, no solamente en lo referido al pago inicial, sino en relación a los pagos aplazados, que forzosamente debieron documentarse a través del contrato de préstamo que se menciona, de

34 ROJ: SAP B 9627:2007, ECLI: ES: APB:2007:9627. AP Barcelona, sec. 18 a , S 20-9-2.007, n ${ }^{\circ}$ 461/2007, rec. 610/2.006.

35 Id Cendoj: 4375a103.rtf. AP Madrid, sec. 22a , S 19-11-2002, rec. 469/2.002. 
la recepción documentada de la subvención, o del libramiento de los efectos mercantiles antes indicados.

\title{
IV. DETERMINACIÓN DE LOS PORCENTAJES DEL PRO INDIVISO PRIVATIVO Y GANANCIAL
}

\author{
Establece el artículo 1.354 CC.
}

"Los bienes adquiridos mediante precio o contraprestación, en parte ganancial y en parte privativo, corresponderán pro indiviso a la sociedad de gananciales y al cónyuge o cónyuges en proporción al valor de las aportaciones respectivas."

PÉREZ MARTÍN ${ }^{36}$, afirma que para comenzar habrá que determinar cuál fue el precio de adquisición, lo que implica el primer obstáculo, ya que es frecuente que el precio que se hace constar en la escritura pública no coincida con el realmente pagado. Será pues el cónyuge que adquirió en estado de soltero el inmueble el que deberá acreditar cuánto le costó la vivienda, resultándole fácil, si concertó previamente un contrato privado y ha guardado los recibos de pago. La complicación, sigue diciendo, se presentará cuando no se concertó un contrato privado, puesto que si no se logra probar cual ha sido el precio real, habrá que estar al precio de compra que consta en la escritura pública. Continúa diciendo PÉREZ MARTÍN, que, conocido el precio inicial de la compraventa, cabe preguntarse si habiendo firmado un préstamo hipotecario para pagar el resto, el precio final será el que pactó con el vendedor o por el contrario deberán tenerse en cuenta los intereses del préstamo hipotecario. En su opinión, aunque es una cuestión que ofrece dudas, parece más justo que el precio del inmueble consista en lo pactado en el contrato de compraventa incrementado con todos los intereses abonados.

Respecto de este tema, las Audiencias Provinciales se pronuncian de manera distinta. La Sentencia de la AP de Álava de fecha $21 / 06 / 2.007^{37}$, acuerda que la proporción ha de calcularse sobre la base de las cantidades netas destinadas durante la vigencia de la sociedad de gananciales a la amortización del principal del préstamo en relación con el neto del precio de adquisición pagado. En su Fundamento de Derecho Segundo dice que una vez instaurado el régimen de gananciales, a falta de capitulaciones y por el puro efecto automático del art. 1.316 del Código Civil, los pagos de las cuotas

36 Obra citada, página 3.

37 SAP Álava, sec. $1^{a}$, S 21-6-2.007, no 172/2.007, rec. 133/2007. ROJ: SAP VI 164:2007, ECLI: ES: APVI:2007:164 
de amortización del préstamo efectuados desde entonces, han de reputarse hechos con cargo a los bienes de naturaleza ganancial y, por ello, como se ha razonado, la parte proporcional de la propiedad de la vivienda deberá ser reconocida con ese carácter ganancial. Proporción que debe calcularse sobre la base de las cantidades netas destinadas durante la vigencia de la sociedad de gananciales a la amortización del principal del préstamo otorgado por la entidad bancaria al demandado en relación con el neto del precio de adquisición pagado. Por su parte, la SAP de Sevilla de 17/09/2.00738 tiene en cuenta tanto el principal como los intereses. Establece en su Fundamento de Derecho Tercero que en el pasivo del inventario de la sociedad ha de incluirse no sólo el capital del préstamo hipotecario que grava la vivienda familiar y que está pendiente de amortizar, sino también los intereses que, no habiéndose devengado aún, figuren en las tablas de amortización y deban ser satisfechos para la completa devolución del préstamo y la consiguiente cancelación de la hipoteca - salvo que se produzca una eventual e inusual amortización anticipada-, pues, aunque se generen tras la disolución, se adeudan mientras no sea abonado íntegramente el principal.

Finalmente, y siguiendo a PÉREZ MARTÍN, lo siguiente, una vez determinado el precio del inmueble, sería calcular que cantidad se abonó por uno de los cónyuges (o por ambos) antes de casarse.

La profesora SEBASTIÁN CHENA ${ }^{39}$, explica con unos ejemplos prácticos cómo calcular el importe abonado del préstamo hipotecario antes, durante y con posterioridad al matrimonio.

a) Antes del matrimonio:

"“Disponemos de estos datos:

- Capital concedido en préstamo: $140.000 €$

- Capital pendiente de amortizar a fecha SS de divorcio (10/06/06): $42.000 €$

* La diferencia abonada entre la fecha de concesión del préstamo y la de la sentencia de divorcio, será $98.000 €$ (140.000 €-42.000€).

*Tal diferencia habrá sido abonada en parte por ambos titulares con su dinero privativo antes del matrimonio y en parte por la sociedad de gananciales.

38 SAP Sevilla, sec. $2^{\text {a }}$, S 17-9-2.007, no 412/2.007, rec. 3862/2007. ROJ: SAP SE 2556:2007, ECLI: ES: APSE:2007:2556

39 Obra citada, página 4. 
*Para determinar que parte ha sido abonada antes del matrimonio, tendremos que fijar:

- Los días transcurridos desde la fecha en que empezó a pagarse el préstamo (01/09/1.994) hasta la fecha de la sentencia de divorcio (10/05/2.006), que fueron 4.269 dias.

- Y de tal periodo ver qué días fueron previos al matrimonio. Es decir, cuántos días transcurrieron desde el primer pago del préstamo hasta el día antes de celebración del matrimonio, que fueron en total 309 dias.

*Con tales datos realizaremos una simple regla de tres, conforme a la cual:

- Si durante los 4.269 días que transcurrieron entre el primer vencimiento del préstamo y la sentencia de divorcio se abonaron $98.000 €$.

- En los 309 días previos al matrimonio, o sea desde el $1^{\circ}$ vencimiento hasta el día anterior a la celebración del matrimonio se pagaron $X$.

— De modo que: (309 x 98.000): $4269=7.094 €$

*'Por tanto, el importe total abonado por ambos ex cónyuges, en estado de solteros, fue de $17.094 €$ (10.000 € de la primera entrega $+7.094 €$ del préstamo). Si se conociera el importe de las cuotas abonadas del préstamo hipotecario, bastaría con sumar los importes desde el primer vencimiento hasta el último previo a casarse."

b) Durante el matrimonio:

"Si se conociera el importe de las distintas cuotas abonadas del préstamo hipotecario, bastaría con sumar las cuotas vencidas a partir de la celebración de aquel y hasta el último vencimiento previo a la fecha de la sentencia del divorcio.

Cuando no sea así procederemos conforme la operación anterior. Y así:

*Partiremos de la cantidad abonada entre la fecha de concesión del préstamo y de la sentencia de divorcio antes indicada, esto es, $98.000 €$

*Tal cantidad habrá sido pagada, como ha quedado dicho, en parte por ambos titulares con su dinero privativo antes del matrimonio, cantidad que ya hemos determinado en la operación anterior, y en parte por la sociedad de gananciales.

*Para determinar que parte ha sido abonada durante la vigencia de la sociedad de gananciales, tendremos que fijar: 
- Los días transcurridos desde la fecha en que empezó a pagarse el préstamo (01/09/1994) hasta de la fecha de la sentencia de divorcio (10/05/06), que fueron 4.269 dias.

- Y de tal período ver qué días corresponden a la vigencia de la sociedad conyugal. Esto es, ver qué días transcurrieron desde la celebración del matrimonio (07/07/95) hasta la sentencia de divorcio (10/05/06) que determinó la disolución del régimen matrimonial, que fueron un total de 3.960 dias.

*Con tales datos realizaremos al igual que antes una simple regla de tres conforme a la cual:

- Si durante los 4.269 días que transcurrieron entre el primer vencimiento del préstamo y la sentencia de divorcio se abonaron $98.000 €$.

- En los 3.960 días que duró el matrimonio se pagaron X.

— De modo que; (3.960 x 98.000): $4.269=90.906 €$

*Por tanto, el importe total abonado durante la vigencia de la sociedad de gananciales fue de $90.906 €$.

c) Tras la disolución del régimen económico matrimonial:

"Cuando no se pueda acreditar quién hizo los pagos, serán considerados gananciales.

En el supuesto que nos ocupa: El importe pendiente de amortizar del préstamo hipotecario a la fecha de disolución del régimen económico matrimonial, fecha de la sentencia del divorcio, 10 de mayo de 2.006, era de $42.000 €$, según quedó indicado.

$Y$ tal importe fue abonado por ambos ex cónyuges por mitad con su dinero privativo con posterioridad a la disolución del régimen matrimonial y hasta su completo pago el 1 de agosto de 2.009.

Finalmente restaría calcular el porcentaje privativo y ganancial, que resume la autora de la siguiente forma:

\begin{tabular}{llc}
\hline $\begin{array}{l}\text { Precio adquisición: } \\
150.000 €\end{array}$ & $\begin{array}{l}\text { Pagado antes del } \\
\text { matrimonio: }\end{array}$ & $17.094 €$ \\
\hline $\begin{array}{l}\text { Pagado durante el } \\
\text { matrimonio: }\end{array}$ & $90.906 €$ \\
& $\begin{array}{l}\text { Pagado tras disolución } \\
\text { matrimonio por ambos } \\
\text { con su dinero: }\end{array}$ & $42.000 €$ \\
\hline $\begin{array}{l}(17.094 €+42.000 €) x \\
100: 150.000\end{array}$ & $39,40 \%$ & Privativo \\
\hline$(90.906 € x 100): 150.000 €$ & $60,60 \%$ & Ganancial \\
\hline
\end{tabular}


Por tanto, en el caso analizado, se incluirá en el activo del inventario como bien ganancial una participación indivisa de un 60,60 \% del bien en cuestión."

Como hemos visto, podría suceder que la sociedad de gananciales finalice antes de terminar de pagar el préstamo hipotecario. Entonces: ¿Qué carácter tiene la cantidad que aún queda por pagar de préstamo hipotecario y quién debe realmente pagarla?

La jurisprudencia menor no es unánime. Hay dos posturas; una sostiene que la vivienda pertenecerá en pro indiviso a la sociedad de gananciales sólo en la parte que se haya pagado mientras estuvo vigente, por tanto, la parte correspondiente al precio de la vivienda que está aún pendiente de pagar pertenecerá al cónyuge que inicialmente adquirió la vivienda, debiendo pues asumir su pago.

Así la SAP Ciudad Real de 28-12-2.00740 explica que el artículo 1.354 del CC establece que " los bienes adquiridos mediante precio o contraprestación, en parte ganancial y en parte privativa, corresponderán proindiviso a la sociedad de gananciales, y al cónyuge o cónyuges, en proporción al valor de las aportaciones respectivas " y acreditándose en el supuesto que resuelve que la esposa adquirió la vivienda siendo soltera y abonó antes de contraer matrimonio más de un tercio del precio pactado en el contrato de compraventa suscrito por la misma, lo que como consecuencia que no pueda considerarse, como hace el Juzgador de la Instancia que, dos tercios de la vivienda formen parte de la sociedad de gananciales, entendiendo la Sala que respecto de la vivienda, el tramo económico que se produce desde la sentencia de separación hasta el pago de la vivienda, tiene así mismo carácter privativo y solamente las cantidades abonadas por ambos cónyuges desde su matrimonio hasta su separación deben entenderse de inclusión en la sociedad de gananciales salvo la deuda que esta sociedad de gananciales pueda tener con la esposa si la misma acredita debidamente el pago de las cuotas de la hipoteca con bienes privativos desde la separación de hecho hasta la separación legal, acreditación que deberá llevarse a cabo en la fase de liquidación. También la SAP de Vizcaya de 10$12-2.004^{41}$ que dice que precisamente en aplicación del art. $1.357-2^{\circ}$ en relación con el art. 1.354, ambos del Código Civil, ha de declararse que la vivienda adquirida por la esposa, en estado de soltera,

40 Id. Cendoj: 13034370012007100465. SAP Ciudad Real, sec. $1^{\text {a }}$, 28-12-2007, $n^{\circ} 383 / 2007$.

41 Id. Cendoj: 48020370042004100507. AP Vizcaya, sec. 4 ${ }^{\mathrm{a}}$, S 10-12-2004, $n^{\circ} 861 / 2004$. 
pasó a tener como cotitular a la sociedad de gananciales que constituyó con el apelante, correspondiendo a dicha sociedad la cuota que representa el plazo pagado por la sociedad de gananciales del total del precio del piso que quedó aplazado. La sociedad de gananciales comenzó con la celebración del matrimonio, por lo que nada pudo adquirir la sociedad de gananciales con anterioridad a su constitución, ni mucho menos es admisible que los plazos que hasta entonces corrieron se satisficiesen con cargo a los fondos de la sociedad. Y la SAP de Almería de 06-02-2.004 ${ }^{42}$ que establece que a partir de la fecha de separación los pagos efectuados por el esposo tienen carácter privativo de este como así lo ha entendido la doctrina jurisprudencial, al señalar que en supuestos como el de autos resultarían de aplicación los preceptos referenciados.

La segunda postura podría ir dirigida a determinar el proindiviso en el momento de la disolución de la sociedad y que la cantidad pendiente de pago se impute en la misma proporción. Así ha resuelto la SAP de Madrid de 25-04-2.00543 que razona: La cuestión centrada en la determinación de la naturaleza de la referida vivienda ha de partir de lo previsto no en el art. 1.355 C.C., sino de lo dispuesto en el art. 1.357 C.C., dado que el primero se refiere a la adquisición de bienes por parte de los cónyuges a título oneroso durante el matrimonio, mientras que en el caso que se enjuicia está acreditada la adquisición de la vivienda por parte de la esposa antes de contraer matrimonio si bien parte del pago del precio por quedar aplazado se realizó ya constante matrimonio celebrado bajo el régimen de Sociedad de Gananciales. Así pues, es de aplicación lo previsto en el art. 1.354 del C.C. por remisión expresa del art. 1.357 del mismo cuerpo legal, es decir la mencionada vivienda ha de tener un carácter mixto, en parte privativo por haber sido adquirido por la esposa en estado de soltera con dinero privativo, hasta la celebración del matrimonio a partir de cuya fecha los pagos han de entenderse realizados con bienes gananciales en virtud de lo previsto en el art. 1.347 C.C, conforme al cual tienen este carácter los bienes procedentes del trabajo así como los frutos, rentas e intereses que produzcan tanto los bienes privativos como los gananciales. En consecuencia, el referido inmueble pertenece en proindiviso a la esposa y a la Sociedad de Gananciales en la proporción, que se determine en la fase de valoración pero teniendo en cuenta como base que todos

42 Id. Cendoj: 04013370032004100083 AP Almería, sec. 3 ${ }^{\mathrm{a}}, \mathrm{S}$ 6-2-2.004, $\mathrm{n}^{\circ}$ 27/2.004. $322 / 2.005$. 
los pagos efectuados hasta la fecha de la celebración del matrimonio tienen carácter privativo al haber sido realizados por la esposa y a partir de la fecha de la celebración del matrimonio hasta su disolución ha de estimarse realizadas con cargo a bienes gananciales. Esta proporción será la determinante para establecer las cuotas de participación en el proindiviso indicado. A partir de la fecha de la disolución de la Sociedad de Gananciales los cónyuges están obligados a amortizar el resto de los pagos aplazados, en la proporción alícuota indicada, es decir la parte privativa será abonada exclusivamente por la esposa la parte ganancial por mitad por ambos cónyuges, (art. 393C.C.). En igual sentido ha resuelto la Sentencia del TSJ de Navarra de 7 de junio de $2.005^{44}$.

PÉREZ MARTÍN ${ }^{45}$, afirma que la opción por una u otra tesis está en la interpretación que hagamos de los establecido en el art. 1.347 CC. Él sostiene que se decanta por la segunda postura habida cuenta que al disolverse la sociedad de gananciales hay que establecer los porcentajes en el proindiviso y ese momento será determinante para atribuir la propiedad, siendo indiferente quien abone posteriormente los vencimientos del préstamo hipotecario, dado que la propiedad permanecerá ya invariable sin perjuicio de los derechos de crédito que surjan del pago de las cuotas. Ello es así, continúa diciendo, porque al constituirse la comunidad ordinaria resulta de aplicación lo establecido en el art. 393 CC, que establece que el concurso de los partícipes, tanto en los beneficios como en las cargas, será proporcional a sus cuotas; en consecuencia, establecida la cuota en el momento de disolución de la sociedad, la carga, es decir, lo que queda de préstamo hipotecario, deberá abonarse atendiendo a dichas cuotas.

\section{CONCLUSIONES}

Las conclusiones que podemos extraer son las siguientes:

a) Cuando el art. 1.357 CC habla de "Los bienes comprados a plazos por uno de los cónyuges antes de comenzar la sociedad...", está haciendo referencia al supuesto en que el comprador entrega una cantidad al adquirirlo y aplaza el resto del pago; la doctrina mayoritaria y la jurisprudencia han interpretado que se

44 Id. Cendoj: 31201310012005100005. TSJ Navarra, sec. $1^{\mathrm{a}}$, S 7-6-2.005, $\mathrm{n}^{\mathrm{o}}$ $5 / 2.005$.

45 Obra citada, página 3. 
equiparan estos pagos aplazados de la compraventa a las amortizaciones de la hipoteca. Resultará indiferente si se concertó un préstamo personal, o si el dinero lo prestó un particular.

b) Si la vivienda familiar se adquirió antes de la vigencia de la sociedad de gananciales, pertenecerá por indiviso a los cónyuges, en proporción al dinero privativo que haya invertido en ella, y a la sociedad de gananciales, también en proporción al dinero ganancial que se haya destinado a la adquisición.

c) Hay que tener en cuenta que la Ley 11/1981 de 13 de mayo de 1.981 modificó la regulación de la sociedad de gananciales que se contenía en el CC. Si la vivienda se adquirió a plazos por uno de los cónyuges antes del matrimonio, tendrá carácter privativo, independientemente de que se haya destinado a vivienda familiar, ya que no existía un precepto similar al art. 1.357 del actual CC, estando vigente antes de esa fecha el art. 1.396 CC.

d) Para determinar cuál fue el precio de adquisición del inmueble será el cónyuge que lo adquirió en estado de soltero el que deberá acreditar cuánto le costó la vivienda; si no logra probar cual ha sido el precio real, habrá que estar al precio de compra que consta en la escritura pública.

e) Las distintas Audiencias Provinciales no coinciden en sus resoluciones sobre si debe sumarse al principal pagado los intereses del préstamo hipotecario a efectos de conocer el precio final.

f) Tampoco coinciden las Audiencias Provinciales en sus sentencias sobre el carácter que tiene la cantidad pendiente de pago del préstamo si la sociedad de gananciales termina antes de finalizar su pago.

\section{BIBLIOGRAFÍA}

ANTONIO JAVIER PÉREZ MARTíN, "Tratado de Derecho de Familia, Vol 1: Regímenes Económicos Matrimoniales, Constitución, Funcionamiento, Disolución y Liquidación”, Lex Nova, pág. 475 y 476, Valladolid, 2.009

JUAN MONTERO AROCA, "Disolución y liquidación de la sociedad de gananciales”. $4^{\circ}$ ed. Tirant lo Blanch, Pág. 376 a 379, Valencia, 2.014. 
MARTA SOLEDAD SEBASTIÁN CHENA, "La liquidación de la Sociedad de gananciales, enfoque práctico de los aspectos sustantivos". Tirant Lo Blanch, pág. 173. Valencia, 2.016.

MARÍA LINACERO DE LA FUENTE, "Tratado de derecho de Familia. Aspectos Sustantivos". Tirant Lo Blanch, Pág. 250, Valencia, 2.016 .

CÉSAR BELDA CASANOVA, "El artículo 1.357-2 del código civil o una forma irregular de aportación a la sociedad de gananciales". Diario La Ley, Sección Doctrina, 1998, Ref. D-70, tomo 1. Ed. La Ley. Pág. 8 a 12.

CARLOS VILLAGRASA ALCAIDE, "Derecho de Familia”, Ed. Bosch, Pag.196, Barcelona, 2011.

FRANCISCO BERJANO ARENADO, "Constitución de hipoteca a cargo del matrimonio sobre vivienda adquirida por precio aplazado en estado de soltería. ¿carácter privativo o ganancial? Foro abierto. El Derecho Editores, Boletín de Contratación inmobiliaria. Fecha de publicación:01/05/2.004. Pág. 2. EDB 2004/115909

JUAN ÁNGEL MORENO GARCÍA, “Constitución de hipoteca a cargo del matrimonio sobre vivienda adquirida por precio aplazado en estado de soltería. ¿carácter privativo o ganancial? Foro abierto”. El Derecho Editores, Boletín de Contratación inmobiliaria. Fecha de publicación: 01/05/2.004. Pág. 3. EDB 2004/115909

VII. ÍNDICE DE RESOLUCIONES JUDICIALES

\section{VII.1. Tribunal Supremo}

STS de 31/10/1.989 (sin número de recurso)

STS de 9/3/1.998 (RC 92/1994)

STS de 4/10/1.999 (RC 310/1995)

STS de 4/12/2.002 (RC 1302/1997)

STS de 3/11/2.006 (RC 60/2000)

STS de 25/3/1.993 (RC 1874/1990)

\section{VII.2. Tribunal Superior de Justicia}

STSJ de Navarra de 7/6/2.005 (RC 32/2004). 


\section{VII.3. Audiencias Provinciales}

SAP de Madrid de 19/11/2.002 (RC 469/2002)

SAP de Vizcaya de 10-12-2.004 (RC 58/2004)

SAP de Almería de 06-02-2.004 (RC 316/2003)

SAP de Madrid de 25-04-2.005 (RC 788/2004)

SAP de Valencia de 8/6/2.009 (RC 312/2006)

SAP Madrid de 8/9/2.006 (RC 1032/2005)

SAP de Madrid de 17/1/2.007 (RC 302/2006)

SAP de Madrid de 8/9/ 2.006 (RC 1032/2005)

SAP de Asturias de 17/05/2.007 (RC 78/2007)

AP de Álava de 21/06/2.007 (RC 133/2007)

SAP de Sevilla de 17/09/2.007 (RC 3862/2007)

SAP de Barcelona de 20/9/2.007 (RC 610/2006)

SAP de Málaga de 26/3/2.008 (RC 572/2007)

SAP de A Coruña de 12/11/2.010 (RC 371/2010)

SAP Vizcaya de 20/6/2.011 (RC 180/2011) 